\title{
Changing Nature: Stacy Alaimo and Cary Wolfe at ASLE
}

The Tenth ASLE Biennial Conference: "Changing Nature: Migrations, Energies, Limits" at the University of Kansas in Lawrence was a resounding success, in part due to the plenaries delivered by Rob Nixon, Stacy Alaimo, and Cary Wolfe, among others (thanks again to Paul Outka for his wonderful work organizing this conference). In the interviews that follow, Alaimo and Wolfe each discuss and extend some of the ideas presented in their joint plenary, touching on their past and current work. Alaimo's talk, "Composing Blue Ecologies: Science, Aesthetics, and Animal Studies in the Abyss" asked, "At the start of the 21st century, even the life dwelling in the deepest realms of the ocean is precarious, as industrialized fishing, drilling, mining, dumping, climate change, and acidification threaten marine ecologies. What would it mean, what would it take, for people to care about life on the ocean floor?" Alaimo argued that the political will needed to create protected areas in the global seas depends upon the kind of data and images that highly visible "big science" (as well as activist sciences) provides, such as the ambitious Census of Marine Life project.

The project frames images of sea creatures in ways that transfer "an immediate, popular, visual sense of 'value' to both the project of the census and to its 'discoveries.' The frames are not subtle; indeed their reflexivity, and the frames within frames, embody an argument about vision and value, enframing as care rather than commodification." Quoting Rancière, Alaimo's talk ultimately posed the question: if "politics consists in 'refiguring space,' could representations of diverse and 
multitudinous sea creatures reshape oceanic geopolitical territories as zones of concern for sea cucumbers, squid, copepods, hydrothermic vent snails, hydromedusas, cuttlefish, black swallowers, sea angels, Dumbo octopod, flamingo tongue snails, fatheads and other creatures?"

Wolfe's plenary, "Humans, Animals, and Recent Biopolitical Thought," approached the politics of our relations with other animals by insisting on the importance of bringing two independent intellectual genealogies - animal studies and biopolitical thought-into conversation with each other. "Animal Studies has been primarily a North American and British phenomenon, and has worked mainly within an ethical framework, while biopolitical thought has been largely a Continental phenomenon and, more recently, has contained a strong component of Italian political theory and philosophy (Agamben, Esposito). Thinkers such as Donna Haraway have complained, and rightly so, that biopolitical thought has stopped at the water's edge of species difference, but I argue that, because race is a fundamental operator for biopolitics, this genealogy can be of great use in thinking about the plight of human as well as nonhuman beings, because you can't talk about biopolitics without talking about race, and you can't talk about race without talking about species." Wolfe argued that once we understand how biopolitics "traverses species boundaries" we can more fully confront problems like factory farming. In both their remarks, Alaimo and Wolfe asserted the concept of politics as immediately necessary for engaging the grave, complex ethical and ecological problems (indeed, questions of care) shaping the world.

\section{Interview with Stacy Alaimo}

$\mathrm{H}$ : In the Q\&A following your plenary you mentioned that you are uncomfortable with the term ecofeminism. Early on, the movement did have moments of embarrassing essentialism, not that it's a bad thing to run naked in the moonlight. [S. laughs] There are, of course, materialist ecofeminisms.

S: Yes, the critique of militarism and such. I know that Donna Haraway writes about having done some of that kind of protesting, and I was doing that sort of protesting in the 80's, against apartheid, nuclear weapons, and situations in Central America. I went as a student to the capital and marched. I was part of a group called "Women Against Military Madness" in the Twin Cities (one of the best things about this was one of the members was the police chief's wife, and she would get arrested for civil disobedience around, say, the National Guard being used to go down to Central America). And I 
participated in door-to-door activism for various feminist and environmentalist causes, though not usually as the same thing.

Now I would like to do something that is really hands-on. My dream would be to be able to go with a group of people scuba diving to clean up the oceans. Because of the academic and intellectual work that we do, I'm craving that kind of hands-on action in the world, something tangible. There's all of this plastic in the oceans that would kill animals, and getting rid of it would be nice, as a complement to the intellectual work we do.

H: I couldn't agree more. While we're on the subject of intellectual work, do you plan to present work at another ASLE conference, or maybe the next meeting of SLSA (Society for Science, Literature, and the Arts)?

S: I've been to SLSA. I was there last year; we had two panels on aquatic creatures, with Ron Broglio, Joni Adamson, and others. This year I'm going to the 4-S, with Eva Hayward, Stefan Helmreich, Nicole Starosielski, and Kim DeWolff.

H: I'm sorry I missed those panels, particularly as I am the ASLE representative at SLSA.

S: Oh, I used to do that. I used to be the ASLE representative at SLSA. I would put together SLSA panels for ASLE and ASLE panels for SLSA because I thought there needed to be much more conversation.

H: And, thanks to your work, there is now a core group of people who attend both conferences.

S: There are more people than there used to be. We used to have to search for people. Okay, I'm going to be good now and answer your questions.

H: And I'll try to be efficient. I really enjoyed your talk; I think everyone did. Is there anything more you'd like to say about the Census of Marine Life project? For example, what brought you to marine ecology after the last book?

S: Well, since I had thought through the idea of transcorporeality pretty thoroughly, and material feminisms, and new materialisms, I really wanted to try something completely different. When I start a new project, I pose a question that's a theoretical and a political problem. I'm a theory person and I'm also a cultural studies person; I always want to find those places where the theory isn't quite working and a real problem in culture draws some sort of attention to it. And I have to find something that sincerely puzzles me, something that I feel very uncomfortable with. There's this concept of productive bafflement (Calvin Thomas has a piece called "Productive Bafflement") and I believe this about the academic work, that you should go toward the 
thing that baffles you most. So, I wanted to try and get away from the concept of transcorporeality and dig through something else. I had seen the census of marine life and I had been reading more about all the various crises in the ocean, and I thought it's very hard to extend a concept like transcorporeality to the bottom of the sea (if that even makes sense; I'll come back to that).

I wanted to explore other ways of thinking about our relations to these creatures, because they're so incredibly different and distant from us. In terms of animal studies paradigms, I wanted to see what the limits of some of these things are. A lot of the animal studies books have to do with relations to companion species, with kinship, affinities, or likenesses, but what do you do with animals that are so far beyond that? We know almost nothing about these ocean creatures. And then, as a science studies person, I really wanted to think through this idea of how the aesthetic is operating through science and what that means.

$\mathrm{H}$ : A book just came out (I thought of it during your talk) on the aesthetics of disease-did you by chance see the BBC article on it? It is full of stunning images of diseased human body parts seen through a microscope. Though this is back to corporeality again ...

S: Interesting. I would like to see that. Ironically, I was trying to get as far away from the idea of transcorporeality as possible, to do something new, because I'm afraid of doing the same thing over and over. I think the Zen idea of "beginner's mind" is always a good one. And I've never worked on the aesthetic before. Never. But then, ironically, even though I was trying to get away from transcorporeality, I got a number of quite wonderful invitations to contribute to projects seeking to create the new field of material ecocriticism. I wrote an essay for a special issue of ISLE on Material Ecocriticism that Heather Sullivan and Dana Phillips edited, a companion piece for Serenella Iovino's and Serpil Oppermann's Material Ecocriticism, and another piece for Jeffrey Cohen's Prismatic Ecologies. Because I was so immersed in researching the ocean, I did end up thinking through how transcorporeality includes the ocean, and I did pieces on that, bringing in a lot of ocean activism and activist films, activist websites, and activist art, all trying to get at some of these same sorts of ideas in new materialism about materiality in something like plastic, the material agencies in plastic. This is the piece that's coming out in Material Ecocriticism; the book is not out yet, but a related piece is in ISLE.

I have done a lot of work now on the ways in which activists try to connect the ocean to the materiality of our everyday lives. It's a very transcorporeal idea. So, I have the transcorporeality in all the new materialism stuff and then this sort of transitional "ocean-as-transcorporealand-the-new-materialist-ocean" work. As I move forward with my 
new book I really want to look back, at least to William Beebe. I did archival research on Beebe at Princeton, on some of his accounts of deep sea animals. So, I want to get at how scientists but also writers and activists make sense of these creatures.

H: What do you think of the term extremeophile?

S: Well, Stefan Helmreich has a piece on that, on forms of life, and I think that's all really interesting. I'm not sure if I will work with it or not.

H: I am curious about the use of the word as a category in this context because the organisms you're looking at are so unlike us that they're often (and, obviously, problematically) called "alien."

S: The piece that's coming out it in Greg Garrard's Oxford Handbook of Ecocriticism is about that, in part. I critique a few James Cameron films that portray the ocean as alien, which is not helpful. One of his films is about encountering aliens in the sea. I don't know if you know that one-The Abyss.

H: I think I've seen that.

S: It's been a long time since I wrote this piece. So there's that one, and one about the science of the deep sea. My feminist critique is that it is ultimately all about imposing a transcendent notion, because Cameron and the scientists keep saying that the reason why the deep seas and vent life are so interesting is because they help us imagine whether there's life on other planets. For them, that's the important thing. So the sea, going down, is continually subordinated to the transcendent rise of the "real science," which would be learning about other planets (over and over in the film). At the end of the film, even as it's supposed to be about science, the scientist puts her hand on the window of this submersible against what at first looks like some kind of sea kelp, but then becomes the "hand" of the alien. To me, that's all about getting out of any kind of sense of responsibility for the damage we have done, because this is actually an environment that's part of our planet, and it's full of our garbage and waste. To say "ooh, these are alien" is a pretty ridiculous sort of way of avoiding moral or ethical responsibility to these creatures.

$\mathrm{H}$ : Sure. And it's another way to market the oceans as spaces for colonization.

S: Yes.

$\mathrm{H}$ : Justice becomes increasingly complex when we realize everything and everyone is to varying degrees permeable. As your work engages explicitly political thinkers like Rancière, what do you do with questions of justice when certain kinds of harm do not have clear sources or agents? 
S: When I was researching Bodily Natures one of the issues that came up was the hope that, at some point, we'd actually be able to determine which chemicals created someone's cancer which, legally, would be huge. Because right now if you get cancer, or any other kind of disease, it's "well, you're just exposed to all sorts of things, it could be this, it could be that." Or, more likely, people blame it on genetics, which is just the easy way out of looking at the environment while denying any environmental implications. But if that technology develops, that would really change things in terms of legal culpability.

But I think in terms of environmental justice, there are people trying to address those issues on the ground. There's porousness and permeability - toxins travel everywhere-but on the other hand there are also levels at which things are undeniably dramatic. I think multiple chemical sensitivity is interesting because of the fact that in moment by moment reactions your body is actually telling you something is wrong, rather than having to go do the research. It doesn't much matter if you can find the research or not in the moment. If you walk into a room and the room is making you sick, you leave the room. There's a way in which the immediacy of the bodily reaction makes that syndrome really interesting for these issues. It cuts through a lot of the layers of mediation and denial.... One of the problems too is the kind of ill-fit between the environmental illness paradigms and disability studies. That's something that interests me too. I wrote about that in Bodily Natures.

H: I was wondering if you wanted to talk a little about climate change, given your new work.

S: One thing that has interested me for a long time is the role of the domestic. When I wrote On Domesticated Ground the argument was that feminists of all sorts were thinking of nature as outside of the domestic space. Instead of seeing nature as the site of essentialism, it was in fact the opposite. It was the site where you get away from gender roles, gender norms, gender essentialism, and sexual norms. It was a queer space, a gender minimizing space, this almost nascent poststructualistfeminist space. And so, I was really critical of this "what you can do at home to save the earth" movement that was going on at the time, because I worried that posing the domestic as the mediator between the citizen and the political realm, the public sphere, was really problematic. It put all of the work on women, for one, but also there are a lot of things we can't solve at home. Clearly, we need regulations, we need oversight, we need different laws, we need technologies, we need all of these things that you don't have in your kitchen.

On the other hand, while I still believe my early critique, it seems we don't really have much democratic power in capitalism. I think 
now I'm embracing the idea that there's something to be said for thinking through your everyday life, and feeling like your everyday life actually has material impact on the world and that you can be an ethical and political being in the smallest of ways. There's something really satisfying about that. So, thinking in terms of climate change of course means considering how your carbon footprint increases with almost every single thing you do. That can be paralyzing and guilt producing, but also liberating; you can also embrace the many possibilities for reducing your carbon footprint. And I think that's important. One of the best moments we had in one of my classes was the day my students had read a book about climate change. We read one of Mark Lynas' travel books, in which he went to various places and talked about how the climate was affecting things. When he was in England, he told people that because of the shifting habitat, this newt would have to cross a giant highway to survive. And there was no way it was going to make it; the odds for this newt's survival are very low. And there's something about that story that really hit them. After we read that, we had class every day with the lights off, even when it was sort of dark outside. Because that's energy. That's carbon. That's climate change. We turned the lights off every day-they insisted on it. They directly connected it to that newt. [laughs] It really was great.

So I think that those connections are important. They're mediated, of course, by knowledge, by science, by politics and everything else. It's not direct but it doesn't have to be. And it doesn't have to lead directly to the newt. It's just that idea that everything that you do does have some sort of impact, and that's really interesting in terms of thinking through basic questions like, "What is ethics? What is politics? How do we function in this world?" To think of ethics as something defined by a Judeo-Christian history of sex laws seems absurd to me; it seems ridiculous. Who cares who anyone has consensual sex with? Climate change redefines the ethical terrain.

H: Moving sideways, but only slightly, has the idea of nonhuman cultures informed your work on marine life? Perhaps something like Hal Whitehead's book on sperm whales?

S: I'm bracketing mammals because I'm trying to understand what we make of those creatures that we don't know very much about. Scientists don't know much, nobody knows much, so what does that mean? But I'm a firm believer that all sorts of animals have social worlds and social lives, and I teach that concept. But because of the nature of my work, I haven't written about it much.

H: I can see why you want to focus on creatures that are quite different. 
S: I think it's a difficult thing that someone needs to write about so that's where I'll go. I'm a scuba diver, and I love whales and dolphins and all of the charismatic megafauna; who doesn't love them? It would be great to study them, but a lot of people have written about them. As a cultural studies person, I always try to head toward what I think needs the work, and I think the thing that needs the work is the deep seas, because they're completely unprotected. They have few advocates. They're just sort of "out there" and capitalism, industrial fishing and mining, are ravaging them, and it's all being done pretty much invisibly.

$\mathbf{H}$ : Yes, international waters ...

S: Yes, anyone can do whatever they want, basically. It is an immense pillaging of the seas. I think this is a serious issue and I want to try and do what I can with it.

$\mathbf{H}$ : And if I'm remembering your plenary correctly, it is also an experiment in stretching our sympathy.

S: Yes, without making it into some kind of science-fiction alien fantasy. So Cameron, for all of his exploits going down to the deep sea, spending millions of dollars going down there, he has a history of just making it into fiction. And that's what he's going to do, actually, with his footage of going down to the Mariana Trench; he's putting it into the next Avatar film. So there's this direct fictionalizing of it, and I know that people who do theory make something very interesting of that, but on the other hand sometimes it's not useful to fictionalize this part of the world with these creatures because they're actually living creatures and we have to come to grips with them as living creatures. And if we're always fictionalizing everything, I think we have to be worried about that. That's why I go to Bruno Latour's chain of mediations and circulating reference because I want some sense of the real coming through, and not just all this made-up shit with bizzaro animals there to entertain us.

$\mathbf{H}$ : Countering the idea that narrative can solve all problems.

S: Yes, that narrative can fix everything. But could we go back to Rancière? I'm happy since you actually know his work and that was Cate's [Sandilands] reaction too, that neither of you thought that my use of him was crazy.

H: I was thrilled. Wolfe gives him, as he said in his plenary, a bit of a kicking. Of course aspects of Rancière's work are problematic. But you can use what's useful.

S: Feminists have done this for a very long time. We take whatever we want and pirate it.

$\mathbf{H}$ : Yes. His notion of politics helped me articulate the way in which a community of beings is political, not simply "social."

S: It really helped me think through sea creature images. When I presented a very early version of this in Alberta, someone stood up in 
the audience and said, "You can't read Rancière that way! You can't do it!" And I said, "Why not?" Since then, Jane Bennett has produced a posthumanist reading of Rancière.

Bennett talks about being at a conference with him, at which he said that absolutely none of this posthumanist stuff about animals counts. But she concludes his theory still works in this context. And we wouldn't have feminist theory, frankly, if people didn't say, okay, this theory is completely denigrating the movement but let's do this with it.

$\mathrm{H}$ : And many of our favorite literary works.

S: Let's play with it and see what happens.

H: I wanted to ask you, as a science studies person, about something Rob Nixon said in his plenary, his concern about "quantitative creep" in the humanities.

S: "Quantitative creep" ... what does that mean?

$\mathrm{H}$ : Well, it seems it may mean a lot of things, but I think he was referring to the way in which, when the humanities are under attack (when legislatures all over the country are cutting funding to state schools, etc.), some academics look for ways to make their work seem quantifiable. Or start trying to incorporate "data" to make their work seem "relevant" to other models of knowledge or to the idea of profitability, to make literature and philosophy and the like "valuable" in such terms (which degrades both the humanities and the sciences). How do we, how should we, approach interdisciplinary work in these difficult times?

S: I think that environmental studies, which deals with the actual material world, has to incorporate science. But I think that we need smart ways of doing it, and that's where science studies theory, and other theory comes into it. The funny thing to me is that when I talk to scientists they think our work is valuable. For example, when I talk to this coral reef specialist at UTA and I tell her about my work, she thinks it's so important. She thinks what we can do in the humanities as far as making these ideas interesting and accessible, putting together arguments and making connections by drawing on science, is important. I think sometimes people in humanities are their own worst enemies because they assume that other people will discount them, and my encounters with scientists have not suggested this at all. I think there's often a great mutual respect, or there can be, and I think that we need to pose questions that are difficult, relevant, and important. And then use whatever we can use to answer those questions. I think the whole idea of having these sorts of disciplinary parameters in advance is foolish. I don't see how it gets us anywhere. And as someone who's a feminist theorist, a cultural studies person, and an environmentalist, 
it's all about contesting these kinds of boundaries, because if you want to do something useful you need to make connections across things.

H: I agree.

S: And to me science studies means I trained in theory, literature, and the humanities. I engage with science, I read it, but I'm not producing science. But I can offer this kind of approach to it, I think, and other people who are in the humanities can offer a different sort of approach to it, and think through issues and assemble connections. We have all sorts of things to bring to the table. But I don't think that means that we can exclude other sorts of information. In Bodily Natures I even draw on the social sciences and popular epidemiology. When I teach, I try to get graduate students to understand this approach: here's your question; what sorts of things would answer that question? And don't just make shit up. I think that's the worst thing about our discipline. I think we sometimes train people to think that they can just make anything up.

H: Well, there are times when people don't seem to see the line where close reading and theorizing ends and factual research begins, or vice-versa.

S: Right. Sometimes they will be talking about something that has a factual answer. And I say, "That is a question that has an answer. What you have to do is go out there and find the answer. There are all sorts of studies that would give you the answer to that. Don't just spin out weird theories about it. Find out." I'm a theory person; I believe in theory. But I think we have to be better and smarter and savvier about knowing which sorts of research, which sorts of data, which sorts of approaches, and which sorts of disciplines fit with the kinds of questions we're asking. And then if you want to do interdisciplinary work, figuring out how you bring those things together in a way that's useful. That's what I'm trying to do all the time. And it's sort of intuitive.

H: Yes, it is intuitive. And this perhaps is the gift that our discipline brings to the conversation, intuition about and across various kinds of questions, texts, and bodies of knowledge.

S: Yes. And it's a little scary. You can mess up.

$\mathrm{H}$ : When your work's intuitive, you're always bringing so much of yourself to it, and in animal and environmental studies the stakes are so very high. So just one last question, what are you reading right now?

S: I love Nicole Shukin's book.

H: Animal Capital? Me too.

S: Love that book. Actually, I was thinking about it on the walk home. I was thinking about how Animal Capital is in some ways, or 
could be, considered a kind of mirror image to the politics of visibility that I'm trying to talk about with the sea creatures.

$\mathbf{H}$ : Yes, the way she looks at animal materialities in systems of production and consumption.

S: It's the visibility that's all around us that's invisible. So this [pointing to the table, pointing to the chair], was this an animal, was some part of an animal used to make this, where are the animals in this room that we're not seeing? So I was really struck by this sense that if you take Shukin's work and then you take what I'm trying to do with the deep sea creatures and Rancière, and you put them together, you have this kind of distant bringing-into-visibility. Her work brings into everyday life the visibility of the animals that are rendered all around us. I wish I had given that answer to one of the questions after the plenary, I think maybe Cate's question, about biopolitics. I think you could make this parallel-maybe not with Cary's work as muchbut with Shukin's work and my work and biopolitics. I think it would work out really nicely.

H: I do too. I sat in on a seminar she ran at ASLE in Canada. There's a core critique of capitalism that's dialectical, in Shukin's work and your work, and it doesn't happen often enough.

S: I agree. This has been so much fun. It's great to talk to you. And you know the interview format actually allows for a more substantial conversation than just chatting, so I appreciate that. That's great.

$\mathrm{H}$ : I've had a lot fun too; this has been very interesting. Thank you.

\section{Interview with Cary Wolfe}

$\mathrm{H}$ : What are your current thoughts about posthumanism?

C: That term is problematic, but I guess there's no getting away from it-from any of these terms. I think it's easy to overinvest in the work that they do and don't do, and that work is different conceptually versus institutionally. Some of the different kinds of investments people have in a term like "ecofeminism" are for institutional, not conceptual, reasons. That asymmetry often gets lost, I think, in debates. [Wolfe and Alaimo had a question on ecofeminism after their joint plenary]

$\mathrm{H}$ : We should actively re-engage such terms, particularly potentially useful ones like ecofeminism. In his plenary, Rob Nixon talked about his new work as, in part, a continuation of "slow violence," for example.

$\mathrm{C}$ : What's he working on right now?

$\mathrm{H}$ : He's going back to look at the concept of the anthropocene itself, what that means in the geological community and its political 
implications, given how unequal humans are in terms of their agency in the world already. We are in the "Age of Man," with greenhouse gas emissions and the rest but, on the other hand, it's really the "Age of Some Men and Not Others."

C: I was involved in a big event on the anthropocene in January at the House for World Culture in Berlin. It was big, a three-day thing, with probably around twenty invited speakers and keynotes. Claire Colebrook and I had an hour-long dialogue onstage about the idea of the anthropocene. [This is available on youtube: http://www.youtube. com/watch? $=$ YLTCzth8H1M]

$\mathrm{H}$ : What else are you working on at the moment?

C: An art project. When I was a student I won a couple of Academy of American Poets prizes, and I was faced with a decision about whether to pursue an MFA or a $\mathrm{PhD}$. So, I quit writing poetry for a long time but now I'm involved in a big collaborative project that has a few different components with Maria Whiteman, who works in image-based art. The project involves photography and video, and for some of these pieces I've written texts. I wouldn't describe them as "poetry" in the sense that would appeal to professional practicing poets, but most people are going to see the texts as poems. They're different because I produced them in this context of pre-existing raw footage of images, so they unfolded in dialogue with this video material and photographs. It's a different compositional process-even my relationship to the text produced is different. And the poems are pretty long; each text is about four pages, very vertical. They're part of four video pieces that are part of a larger project on animal movement and migration. We have a photo essay coming out in a journal in Canada-an essay I wrote in conjunction with a series of diptych images Maria put together.

Well that's one of the things I'm working on right now. That whole body of work will probably take a couple of years. I'm also working on a book on Wallace Stevens. My literary field is actually American Modernism and, within that, modernist poetry. My first book is on Pound, from my dissertation on Pound and Emerson. The funny thing is, I've been teaching this material for the last twenty plus years. The way that my academic career developed, everywhere I was had a $\mathrm{PhD}$ program and a 2/2 load. Typically, three of those courses would be undergraduate and one graduate, and on the graduate side I got pulled more and more into teaching "theory." That led into the matrix of work on systems theory and animal studies that occupied me over the next however many years. But all along on the undergraduate side, and selectively on the graduate side, I continued to teach this literary material. There's a graduate course that I teach pretty regularly called 
"Genealogies of American Romanticism" on Emerson, Cavell, Stevens, through Luhmann and Derrida, but I've never had time to just sit down and write the Stevens part. The book is tentatively titled Wallace Stevens' Birds: the poetics of extinction. There's a snapshot of part of the argument in the Stevens chapter in What is Posthumanism?, the systems theory rearticulation and retheorization of the core paradoxes in the romantic genealogy that people see in Stevens and Emerson, but that's only part of the argument.

H: I look forward to reading it. This would be enough to occupy anyone for a few years, but do you have any long-term plans for another theory project?

C: There is a third project that has evolved quickly over the last several months, a political theory project on biopolitical thought after biopolitics. That project took shape from a graduate seminar I was teaching on systems theory and biopolitics last year. The topic of the seminar was systems theory, but biopolitics was going to be one of three examples at the end of the course of how systems theory can help you rearticulate and redescribe different theoretical problems. I had Judith Roof come in to the course and talk about questions of gender and sexuality, and I was going to do a class on how systems theory makes biopolitics look different. What I did in the course of thinking about that part of the class was to go back to Esposito's work on biopolitics, specifically, his insistence that the immunitary paradigm is what Foucault really doesn't recognize as constitutive of the biopolitical problematic. The immunitary paradigm, as Espositio articulates it is, in deconstructive terms, the logic of the pharmakon and, in systems theory terms, it's a theorization of a self-referential autopoietic system. Esposito actually references Luhmann, and he references Haraway and other people who have invoked this immunitary and autoimmunitary model. But he doesn't really do very much with it. A lot of it is very between-the-lines; so I said, I'm going to go through and systematically cross-map Luhmann's theorization of the self-referential autopoetic nature of the political with the immunitary paradigm in Esposito. What has happened is that the project has gradually gotten bigger and bigger because it came into conversation with work by other people who continue to think about what biopolitics is interested in beyond the codification of biopolitical thought that we're now stuck with. As you know, Esposito is trying to think an affirmative biopolitics outside of the thanatopolitical drift you get in someone like Agamben.

H: I really enjoyed your joint plenary with Stacy. Both of you placed an idea of politics at the forefront of your arguments, as opposed to an abstract ethics which, as you have said, tends to dominate animal studies. 
C: Well, ideally, what it will force will be a much more complex understanding of the political and of politicization, which are not the same thing . . . in ways that won't necessarily eventuate in the political having a more central place in critical thought. For example, one of the things that I'm going to argue in this political theory project I'm working on is that if you actually cross-map the paradigm of the immunitary mechanism of biopolitics with the systems theory theorization of the political as an autopoetic system, what you realize is that, paradoxically, insofar as you insist on a strong concept of the political, you actually end up with a very weak concept of the political-weak in the sense of the political being a domain that can overdetermine and steer other social systems. The force of the political-if you actually carry through the theorization of self-reference in a way that Esposito doesn't-paradoxically becomes more attenuated the more you insist on a rigorous concept of the political. And the problem with Esposito is that he wants to have it both ways. He wants to insist that the immunitary mechanism is fundamental, and yet he wants to retain a very broad sense of the efficacy and force of the political, of the sort that you have in Agamben. So the intervention I'm trying to make is to say no, if you actually want to theorize the political as a self-referential immunitary mechanism, you will be forced to acknowledge that the political ends up having a diminished force in contemporary culture.

Now what does all this have to do with biopolitics? It dovetails with attempts in current biopolitical thought by people like Tim Campbell, Gregg Lambert, Jeff Nealon and others to say well, if it's the case that this sense of the political is bound to end up being weak, insofar as the theorization of it is strong, then we must ask what are the processes of politicization that actually take its place? One answer is Deleuze's late work on control society. It's kind of a sequel to his book on Foucault, so you can take Deleuze's reading of Foucault, his remarks on control society (in his late conversation with Antonio Negri) and say, we have to think a new logic of the political and politicization that doesn't end up caught in this sort of paradoxical, self-defeating status that biopolitics eventuates in. Another example is the work of Tim Campbell, who translated Esposito's Bios for the [University of Minnesota Press] Posthumanities series, and who wrote a great book in the series called Improper Life. Tim is very interested in what Italian political philosophy calls the impolitical, or the unpolitical, in relation to the political proper, as a resource for thinking questions and issues of community outside of a strictly delimited political framework.

So the question becomes, how do you continue to press the questions that are pressed by biopolitical thought and not end up in this 
kind of tragic drama of the political that we end up with in Agamben? One way to think about it - to put it in shorthand -is that there's a relationship between systems theory and Foucault, and then Deleuze and his reading of Foucault, that attempts to re-think the political outside the more classical parameters ruled by political thought, whether you're talking about Agamben or Esposito. So that's the third project I'm working on right now.

$\mathrm{H}$ : Did you arrive in Kansas in time to see or hear any of the tornado warnings? If memory serves, somewhere in the Q\&A someone asked a question about complex or overwhelming systems and the increasingly polarized (and, for many, disempowering) experience of place, the way in which various groups of people experience place in such radically different ways.

C: And not just people.

H: Right. When I say people I mean ...

C: ... nonhuman persons included ...

H: Yes.

C: I think that's right. In the Q\&A, I was making the point that there's no generic, one-size-fits-all answer to these questions that, to me, has much political force. Now a traditional reply would be to say that such a position is somehow hampered or enfeebled or lacks veracity as "critique." And my point is exactly the opposite. My point is that actually it's because such answers are nongeneric, because they are very situational, and have to do with the pragmatic contingency of the iterative instance, that's precisely why they have political force; that's why they have traction. So whenever you're talking about conjugating the relationship between a so-called universal phenomenon-let's take global warming as an example-and how it's experienced by different communities or different persons, it goes without saying that that always has a nongeneric character. So the universal nature of the problem never exists "as such" in some kind of generic transparency. It only exists as it's iterated through these particular instances. I see that as a political resource for carrying out these kinds of critiques, even as the political alliances that can eventuate from them have to do with this "universal" phenomenon commonly called global warming or climate change. I take it for granted that there's no view from nowhere, on any political question.

H: Yes, and what does this mean for an inclusive theoretical, political (even imagined) space, for mass movements necessary to confront global power's very material and virtual existence?

C: I don't think those are mutually exclusive at all. I think those communities have more traction, in relation to each other, because they're not presuming to step outside of their own location. So, having 
said that, the next shoe to drop-and I talk about this in Before the Law - is of course the shoe of ethnocentrism, if you criticize the formulation of the traditional rights-holding subject or the subject of politics, and the kind of formalist and conventionalist notion of the political subject that reaches back from people like Hannah Arendt and Rancière.

If you critique the formalist and conventionalist rendering of the subject of rights, which always ends up being grounded in the human being's capacity for language, for "meaningful" or "relevant" speech, then you still have to deal with the question of universality. How do you get out of the problem of saying that, well, in these contingent and situated communities, we just care about what we care about and to hell with everything else? That's where the phenomenological and ontological domain has to re-enter as a way to confront the question of ethnocentrism, and this is exactly what Arendt is running into in The Origins of Totalitarianism. What she experiences is a collision between her very formalist Aristotelian idea of the political and of the subject of rights and the fact that suddenly she is surrounded in the wake of World War II by millions of stateless people, who are in the condition of bare life and who have, by her own definition, no political status in precisely those terms. This is where she runs into the problem of what she calls "the right to have rights." And dealing with the right to have rights forces you back into these ontological, phenomenonological questions that we used to talk about in terms of the universal. What I'm critical of in Before the Law is the knee jerk response to this dilemma that you get in biopolitical thought, in the attempt to think an affirmative biopolitics. That is to say, if we start drawing ethnocentric lines of membership in a community (just to telescope all these into one formulation), then that is bound to turn into the kind of autoimmune disorder that Derrida talks about in Philosophy in a Time of Terror, and that eventuates in the Agambenian thanatological paradigm of the camps. So, to put it bluntly, in the bios/zoe distinction, if you start drawing lines between Aryans and Jews, that is necessarily going to lead to drawing lines within the zone of immunitary protection itself. Now it's not just Aryans and Jew, it's blue-eyed Aryans versus brown-eyed Aryans, and now it's blonde-haired blue-eyed Aryans versus blondehaired brown-eyed Aryans, so you get into this runaway autoimmune disorder that actually ends up using that very logic to devour the community that supposedly it's meant to protect. The example that Esposito gives is actually of Hitler, in the bunker in Berlin, as Berlin is being invaded by the Soviets, sending out the telegram that says, "The entire means of subsistence of the German people must be destroyed because they are unworthy, so that the Third Reich can be 
saved." That is the quintessence of the autoimmune disorder produced by this immunitary logic.

So the problem you have to confront-and this seems to me right now of the moment in biopolitical thought-is how do you think an affirmative, positive biopolitics, regarding the vast diversity of life, in ways that don't end up back in this autoimmune disorder but also don't avoid the problem altogether by just saying that we can't draw any lines anywhere-this is what Esposito does. Even if you don't use the word "equal," there's a sense in which, at the end of his book Bios, all forms of life in relation to norms have kind of the same standing. And at that point, "life" is just as blunt an instrument as the human/animal distinction. So the way that I confront this problemand Stacy invoked this in her remarks - is to say, look, you are always going to be drawing lines of some kind, and you're going to do that from a very specific location. And if you didn't do that, your so-called political actions would not have any binding force at all. But you draw those lines in the knowledge that-to put it in deconstructive terms - those actions are always blind, they're always necessarily exclusionary, they're always necessarily contingent, and therefore whoever you think your community is is always under erasure in a radical sense. And in fact, the history of science shows this with regard to nonhuman animal life. The history of science shows that all of these places that we used to confidently draw the boundaries, between those whose lives count as lives and those whose lives don't, are constantly shifting. That's what keeps the zone of immunitary protection from ossifying and hardening and flipping over into an autoimmune disorder. On the one hand, yes you do have to make those decisions, yes you do have to draw those lines and, on the other, you do so in the knowledge of the contingency and blindness of those distinctions, knowing that you will have been wrong, and that it's a good thing that you will have been wrong. That's the only thing that opens the community to futurity and to a constantly broadening membership that you can't sit here right now and anticipate and designate and describe, right?

$\mathrm{H}$ : Contingency and blindness are the conditions of knowledge, and I like the idea (though it also scares me) that it is a good thing that we will have been wrong. Given that (to push the point), what about our relations with the deeply inhuman, geologic time and processes, the ontology of rocks...?

C: I've thought a lot about this with regard to object-orientedontology and speculative realism. We have published, and are publishing, some of that work in the Posthumanities series. The problem is, how do you not end up back in a flat ontology that just evacuates all 
the phenomenological and ontological specificities, differences, and asymmetries that supposedly are the things that you want to hold on to, to open the community to its own difference? Actually I'm not interested in ontology; I think ontology is a misguided philosophical project, period. The problem with flat ontology is that you just end up back in the situation of, well, a rock is a Bonobo. And a rock is not a Bonobo. The way I put it in Before the Law-in this moment where I'm actually talking about Levi Bryant's work, which I like (and this could also be taken in the direction of calling into question some of what Latour is doing as well) - is to say is there not a difference between the chimpanzee used in biomedical research, the cage that the chimpanzee sits in, and the flea on the chimpanzee's skin? And is that not a difference that matters infinitely more to the chimpanzee than it does to the cage? I think that there is a difference. And I think it's a difference that is ethically and politically of the moment. And the problem with flat ontology is that it evacuates those radical asymmetries. Having said that, what flat ontology is right about is that the chimpanzee, like the human being, is an object. It's a concatenation of the material processes that actually, strictly speaking, have nothing to do with the human, which can possibly manifest into something called a Bonobo or a human being. And, in doing so-and this is the important pointsuch processes can create ontological domains that are actually not reducible to their material substrate. This is what Heidegger was right about. Heidegger was right that the being of beings is not a being. It's not an empirical, concrete object. So whatever we're talking about is not a being in the sense of an empirical object. Having said that, what he's wrong about is that Dasein coincides in any way with the human/ animal distinction, in terms of having a world (even in the mode of not having, as he puts it regarding animals), and what he's also wrong about is that whatever Dasein comes from is really in a way just a brute concatenation of material processes that happened quite improbably to eventuate in this thing called homo sapiens.

$\mathbf{H}$ : To link back to your other projects, what role might art have in these formulations?

C: Well, how delimited is the concept of art you're invoking? The reason I ask is the question of the function of the aesthetic in the process of politicization seems to me a little different from the question of the function of art in the process of politicization. In the broader sense, I think the problem is just how picky do you want to be in a democracy about what is considered art? I don't think art-officially, in a somewhat delimited sense-I don't think art is that important in terms of processes of politicization. But I think the aesthetic in the 
process of politicization and democracy is really, really important. And that would eventually lead us into talking about...

$\mathrm{H}$ : And when you say the aesthetic, you're thinking ...?

C: Right, in what register do you want to talk about that? Do you want to talk about it in the register of affect, in the register of some kind of negative capability that binds communities? How do you want to talk about what you mean by the aesthetic, the relation of the aesthetic, in traditional terms, to utility, right? Well, this goes back a little bit to my response to Cate Mortimer-Sandilands' question. ... I worry a little bit about overgeneralizing about what counts as the aesthetic, even within a particular society, for just straight-up reasons of anthropological and demographic specificity.

I think, for me, one person's aesthetic is another person's commodification or decadence or whatever, so we can sit here and list examples of what you might be tempted to call debased forms of commodification of the aesthetic that might have a politically binding force in demographically different kinds of communities. Even within US democracies. So that's why I responded to Cate's question in the way that I did; I think underneath her question there's an impulse to make a generalized formulation about the relation of the political to the aesthetic that is problematic and would give me pause. And, in fact, I would see my reluctance to make that formulation as actually beingin terms of politicization - a democratizing move. So again, I think one place this ends up is in a little different idea of the theorization of the political, and what the political is in relation to processes of politicization. Again, I don't feel tempted to give a one-size-fits-all answer to the relationship between aesthetic and politics. And I think you can just look at the demographic differentiation of US culture to see why. For example, where I live in Texas is such a multiethnic, multilinguistic, multicultural place, especially Houston, that you really have a sense of how different kinds of aesthetics play a different politicizing role in communities, whether you're talking about the Hispanic community, the African-American community, and how those communities do and don't interact. And every time I go to places like Portland or Seattle I'm always struck by this. I always come back to Houston and think, those places are so white; everybody seems to be wearing Mountain Hardware, riding Trek bicycles.

$\mathrm{H}$ : To move toward another kind of disciplinary question, yesterday Rob Nixon spoke about something he called the quantitative creep in the humanities. I was wondering if you might talk about that briefly.

C: It's a huge problem. [Laughs] In fact, I don't know anyone-I mean, I'm sure they're out there, but I don't know anyone who's rah-rah for quantitative creep in the humanities. 
H: Certain administrators perhaps ...

C: Administrators are behind that, but I think the quantitative creep in humanities is an epiphenomenon of a much broader movement that's been happening in the corporate university pointedly in the last 15 years, at least in my experience. Actually, it goes all the way back to the 60's, and the Kerr report on the University of California system, a founding moment of this particular logic. What's going on in the quantification of the humanities is part of the broader phenomenon that cuts across the entire university, and has to do with increasing use of the metrics of accountability.

H: I feel that interdisciplinary work is more important than ever. But some might confuse genuinely interdisciplinary work with scholarship that tries to conform to business models of value or refashion itself into "data" to justify its existence in an environment hostile to theory, philosophy, and the arts.

C: Yes. I guess certain areas of media studies are where you would see that more than anywhere else. It's part of the broader shift to define what counts "as" real knowledge, and if it's not quantifiable and, ideally mathematizable, then it doesn't count as real knowledge.

$\mathbf{H}$ : Speaking of the problem of knowledge, what are you reading at the moment? What do you recommend?

C: My problem is that I'm a little bit of an indiscriminate omnivore, which I guess some people would describe as ...

H: Intellectual promiscuity . . .?

C: . . . it's a familiar experience that if you have broad interests and you do interdisciplinary work, you're always in the room with people who know more about some aspect of what you're talking about than you do ...

$\mathbf{H}$ : Which is great, because then you learn all the time.

C: I'm fine with that, but it just makes for way more projects, you know, than I can take on. But I will go as far as to say that I'm going to continue to actually write more about art - broadly speaking - and do more with art as part of whatever it is I'm working on. I don't know the individual forms that that'll take, but that's going to happen. A lot of my current reading revolves around projects for the Posthumanities series, and for other presses and journals with which I have some kind of editorial involvement. For example, I've been going back through Derrida's book Cinders, which we are going to republish in the series, and thinking about how different the text looks in the context of twenty years of biopolitical thought and the place of fire, ashes, voice, testimony, and the Holocaust in that genealogy. It's a very different book now, in that light. I've also been reading Michel Serres' book Biogea, which Minnesota brought out in their Univocal translations 
series. And Eric Sanderson's book Terra Nova: The New World After Oil, Cars, and Suburbs. And lots of old Wallace Stevens criticism! Harold Bloom, Helen Vendler, Joseph Riddell. It's really remarkable work in its own way - good old fashioned literary criticism!

$\mathbf{H}$ : This has been great. Thank you, again, for the interview.

C: You're welcome.

\section{Acknowledgments}

I would like to thank my graduate student, Jeremy South, for his help with transcription. 